\title{
Entrelinhas entre os hiperlinks: Subliminar de uma nova forma de conceber
}

\section{aprendizagem}

\author{
Interlines between hyperlinks: Subliminate of a new way to conceive learning \\ Interlíneas entre hiperlinks: Subliminado de una nueva forma de concebir el aprendizaje
}

Recebido: 23/06/2021 | Revisado: 28/06/2021 | Aceito: 29/06/2021 | Publicado: 13/07/2021

Bianca Rodrigues Marques Peterle
ORCID: https://orcid.org/0000-0001-8405-947X
Centro Educacional Leonardo da Vinci, Brasil
E-mail: biancapeterle@ yahoo.com.br
Bruno Magela de Melo Siqueira
ORCID: https://orcid.org/0000-0003-2074-5686
Universidade Federal do Espírito Santo, Brasil
E-mail: brunosiq15@ gmail.com
Ernesto Correa Ferreira
ORCID: https://orcid.org/0000-0003-0426-0099
Instituto Federal do Espírito Santo, Brasil
E-mail: ernesto.ferreira@ ifes.edu.br
Paulo Rogério Garcez de Moura
ORCID: https://orcid.org/0000-0003-2659-5383
Universidade Federal do Espírito Santo, Brasil
E-mail: paulomoura.ufes@ gmail.com

\begin{abstract}
Resumo
Vivem-se tempos que se faz necessário a desconstrução de algumas resistências pedagógicas. Adaptar-se às novas frentes virtuais, que tem reconfigurado o mundo numa perspectiva globalizada de costumes e valores mutáveis, leva a um esforço de construção de pontes entre os conhecimentos escolares e os saberes ampliados, sendo premente rever os fundamentos que sustentam o ensino e aprendizagem, encontrando junto aos sujeitos o significado do conhecimento. A compreensão do texto não é apenas a resultante de um compêndio de termos que ali se apresentam, mas reúne um grande número se elementos materializados na interface virtual, ou impressa. A formação de uma amálgama de múltiplos signos alfabéticos (letras, palavras, frases) e semióticos (imagens e sons) para expressar a mensagem pretendida, tornou a linguagem digital um modelo de comunicação que transcende palavras, trazendo em seu bojo modificações na forma de compreensão textual e de pensamento do sujeito que contempla tal interface. Os hiperlinks dispostos nos hipertextos oferecem ampliações sedutoras ao usuário, ao mesmo tempo que escondem armadilhas virtuais, dessa forma precisam ser antevistos pelo docente, na elaboração de sua atividade, com orientações repletas de intencionalidades, levando o aluno a evitar alguns desses atalhos.
\end{abstract}

Palavras-chave: Hiperlinks; Hipertexto; Linguagem digital.

\begin{abstract}
We live in times where it is necessary to deconstruct some pedagogical resistances. Adapting towards the new virtual fronts, which has reconfigured the world in a globalized perspective of changing customs and values, leads to an effort to build bridges between school knowledge and expanded knowledge, being necessary to review some proposals that sustain teaching and learning, finding together with the subjects the real meaning of knowledge. The text's comprehension is not only the result of a compendium of terms that are presented, but it gathers a large number of materialized elements in the virtual or printed interfaces. The formation of a multiple alphabetic amalgam (letters, words, phrases) and semiotic (images and children) signs to express an intended message, made digital language a communication model that transcends words, bringing changes in the form of understanding textual and thinking interface of the subject that contemplates it. The hyperlinks located in the hypertexts offers seductive enlargements to the user, while hiding virtual traps, so it needs to be foreseen by the teacher, in the elaboration of his activity, with orientations that are full of intentions, leading the student to avoid some of those shortcuts.
\end{abstract}

Keywords: Hyperlinks; Hypertexts; Digital language.

\section{Resumen}

Se vive tiempos en los que se hace necesario la desconstrucción de algunas resistencias pedagógicas. Adaptarse a las nuevas frentes virtuales, que están reconfigurando el mundo en una perspectiva globalizada de costumbres y valores mutables, lleva a un esfuerzo de construcción de puentes entre los conocimientos escolares y los saberes ampliados, siendo urgente rever las propuestas (teorías) de enseñanza (aprendizaje) acabadas, encontrando junto a los sujetos el 
real significado del conocimiento. La comprensión del texto no es solo la resultante de un compendio de términos que allí se presentan, pero reúnen un gran número de elementos materializados en la interfaz virtual o de prensa. La formación de una amalgama de múltiples signos alfabéticos (letras, palabras, frases) y semióticos (imágenes y sonidos) para expresar el mensaje pretendido, convirtió el lenguaje digital en un modelo de comunicación que trasciende palabras, cargando en su interior modificaciones en la forma de comprensión textual y de pensamiento del sujeto que contempla tal interfaz. Los hiperlinks dispuestos en los hipertextos ofrecen ampliaciones seductoras al usuario, al mismo tiempo que ocultan trampas virtuales, de esa forma necesitan ser anticipado por el docente, en la elaboración de su actividad, con orientaciones repletas de intencionalidades, llevando el alumno a evitar algunos de esos atajos (desvíos, meandros).

Palabras-clave: Hiperlinks; Hipertexto; Lenguaje digital.

\section{Introdução}

\subsection{Entre reflexões, ponderações e escolhas}

Conceber um texto, como se fazia na tipologia de Gutemberg, encontra entraves na geração com a qual lidamos rotineiramente, os residentes digitais. Tais indivíduos são rodeados de informações multimodais e certamente raciocinam no mesmo formato, ainda que sejam impelidos a fazerem uso do texto vertical, com início, meio e fim. Isso tem gerado mais do que um conflito de gerações (analógico e digital), um choque de realidades entre mundos que se conceberam de forma própria, com abordagens peculiares. Impelir o residente digital a construir sua percepção textual pela lente de quem fez uso, em boa parte da sua formação, de uma matriz física, impressa, pode acarretar lacunas de aprendizagens no aluno, tanto pela apreensão insuficiente do conhecimento quanto pela orientação superficial das atividades, pelo propositor. Na era digital, enciclopédias, periódicos, revistas, jornais, panfletos, entre outros modos físicos de representações, se deslocam para um formato fluido, dinâmico, ao alcance de um clique. Pierre Lévy afirma que,

[...] um texto em formato digital, reconfigurável e fluido. Ele é composto por blocos elementares ligados por links que podem ser explorados em tempo real na tela. A noção de hiperdocumento generaliza, para todas as categorias de signos (imagens, animações, sons etc.), o princípio da mensagem em rede móvel que caracteriza o hipertexto. (Lévy, 1999).

O conhecimento pretendido nem sempre é alcançado, devido à forma como se apresenta ao leitor e ao conflito entre o que se entende por informação e conhecimento. Lévy (1996) aponta que, para entender e memorizar o conteúdo dos textos (impressos), é necessário que os leitores depreendam sua macroestrutura textual e que o oposto é mais difícil, ou seja, abstrair e integrar o sentido de um texto a partir das fragmentações (hipertexto). O excesso de acessos tem levado os alunos a um estresse cognitivo, mesmo que eles (os sujeitos) ainda não tenham se dado conta. Na atual sociedade do conhecimento, é preciso compreender que cognição não pressupõe informação. Segundo Gómez,

A saturação de informações gera dois efeitos aparentemente paradoxais, mas na verdade convergentes: a superinformação e a desinformação. Parece claro que o exagero de informações fragmentárias causa indigestão e dificilmente provoca o conhecimento estruturado e útil. (Gómez, 2015).

O uso das Tecnologias Digitais de Informação e Comunicação, TDICs, já se faz presente em boa parte das escolas, o que se pode questionar é se sua presença se dá apenas pelo aparato ferramental, ou se a sua verdadeira função como meio de proporcionar mudanças significativas na forma de ensinar e aprender está sendo realizado a contento. Computadores, tablets e celulares como objetos, para acessar, copiar e colar, acabam sendo pormenorizados nas suas reais possibilidades de ampliação do repertório sociocultural-linguístico-científico-cognitivo. O professor, na sua função formadora, é quem pode impulsionar o aluno a patamares da compreensão do significado do aprendizado, fazê-lo enxergar além do texto escrito é algo que pode ser alcançado, se uma mudança de concepção for feita através novos letramentos digitais. Não se deve mais conceber aulas 
instrucionistas com o uso da ferramenta tecnológica, a mudança precisa ocorrer em todas as esferas do processo de ensino aprendizado.

Em se tratando de multimodalidade nos ambientes virtuais, que se faz presente além do meio utilizado pelo sujeito para se comunicar, para seu lazer, para seu aprendizado, ela atua no seu subconsciente. A compreensão dos eventos que rodeiam o sujeito é processada conforme a linguagem a ele é apresentada. Devido a tecnologia e a digitalização global, os residentes digitais, que na sua maioria desconhecem as interpretações analógicas, processam a informação e a decodifica utilizando os mesmos recursos no qual está inserido, imersos em um amplo contingente de possibilidades multissemióticos. Para Kenski (2012) o poder da linguagem digital e seus periféricos, influencia cada vez mais a constituição do conhecimento, valores e atitudes. Cria uma cultura e uma outra realidade.

O residente digital, que frequenta as salas de aula, carrega no seu subconsciente um pensamento multimodal, por estar imerso nessa nova linguagem, em sua casa, com os seus pares, e em certa medida na escola. Os recursos virtuais aplicáveis multiplicam diariamente, de forma que acompanhá-los na sua plenitude, para alcançar a real viabilidade da sua utilização, exige do sujeito uma busca constante, em concomitância com reflexões da usabilidade na prática do seu ofício. Valer-se de modismos para acompanhar o mercado e até mesmo os residentes digitais, pode gerar excessos sem funcionalidade e (mal) aproveitamento do que se deseja alcançar, o conhecimento e as reflexões ampliadoras na formação do sujeito. Tais recurso devem instigar o professor a promover uma mudança perceptual de comunicação. Conforme Pedro Demo,

$\mathrm{O}$ apreço a modismos revela, ao fundo, fragilidade teórica alarmante, porque indica que se adere àquilo que mais trai no momento. O mundo das novas tecnologias é propício a modismos, em especial quando se supões que mudanças tecnológicas significa ipso facto mudança pedagógica. Muitas vezes, trata-se de vinho novo em garrafa velha, como é o caso mais típico do uso das tecnologias mais avançadas para "melhorar" a aula instrucionistas. (Demo, 2009).

A inclusão de recursos tecnológicos em uma sala de aula precisa ser pensada num contexto mais amplo do que simplesmente a reprodução de um material analógico emoldurado pelo aparato digital. O professor precisa conhecer a dosagem adequada da ferramenta que vai utilizar, tanto no contexto físico (seus recursos, suas possibilidades) quanto no contexto das conexões cognitivas que pode gerar, partindo do pressuposto que os alunos já estão imersos numa linguagem multimodal vigente, suas relações integrativas e diferenciações progressivas (Ausubel, 1969) podem levar a construção de um conceito distorcido da mensagem pretendida. É preciso refletir a respeito dos avanços tecnológicos, digitais e virtuais, subutilizados na aprendizagem do aluno. Para Bacichi, Neto e Trevisani (2015) a implantação de qualquer atividade ou método pedagógico que seja diferente da aula expositiva centrada na figura do professor merece uma revisão do espaço e da sala de aula. E por que não repensar o espaço escolar? Mais ainda: seria a escola o único espaço de aprendizagem?

Ser proficiente nos gêneros do ambiente digital requer pesquisa, ponderação e reflexão do indivíduo que a almeja, na mais ampla concepção de formação pessoal. A continuidade da aprendizagem será simultânea com as pesquisas e a reflexão sobre a viabilidade do uso de tais ferramentas. Não se pode perder de vista que o foco da busca é a aprendizagem significativa do aluno, que na maioria das vezes tem utilizado os meios tecnológicos sem a orientação adequada, se valendo de informações desencontradas, sem o devido alinhamento, muitas vezes por falta da orientação necessária por parte do discente. A criticidade e o juízo do professor fazem com que o tratamento das informações elencadas possa ser trabalhado, conforme o que se deseja alcançar na construção da cognição dos eventos pelo aluno.

Tomando como ponto de partida as reflexões anteriores, o objetivo do presente artigo é refletir acerca do uso dos ambientes virtuais de aprendizagem com suas possibilidades de ampliação do repertório cognitivo do discente. De que forma as metodologias adotadas pelos docentes podem potencializar o alcance do conhecimento pretendido diante das diversas vias que os hiperlinks contidos nos hipertextos podem se configurar norteadores. Analisar algumas interfaces virtuais com suas 
multissemioses, e como as teorias de aprendizagens recentes discutem a necessidade dos letramentos digitais nos diversos ambientes de estudo.

\section{Metodologia}

A presente pesquisa se caracteriza como uma pesquisa de natureza básica, qualitativa e bibliográfica, segundo Kauark, Manhães e Medeiros (2010). O estudo aqui desenvolvido constitui uma revisão bibliográfica referente aos múltiplos recursos disponíveis nos ambientes virtuais de aprendizagem, bem como as novas teorias de aprendizagem discutem a nova forma de conceber a aprendizagem diante das Tecnologias Digitais de Informação e Comunicação, TIDCs, nas múltiplas formas de se comunicarem conteúdos amparadas pelas ferramentas digitais.

A coleta de dados foi realizada no período de agosto de 2018 a julho de 2020, durante o curso de Mestrado de Educação em Química da autora, utilizando para pesquisa os livros dos autores citados ao longo do artigo, bem como as interfaces digitais elencadas para análise dos recursos multissemióticos comuns à disciplina de Química, que compuseram a linha de pesquisa da autora. Tal pesquisa-ação teve como produto educacional obtido um aplicativo (programa em dispositivo móvel que permite ao usuário executar tarefas específicas), gratuito, com práticas sistematizadas de laboratório aplicadas ao cotidiano, apresentando os fenômenos a serem analisados, utilizando reagentes próprios do dia a dia, denominado Hand Lab. Para isso foi necessário trabalhar na perspectiva dos letramentos digitais utilizando as Tecnologias Digitais da Informação e Comunicação, com leitura e análise de múltiplos livros e artigos que englobam os temas discutidos ao longo deste artigo.

A presente pesquisa utilizou-se de múltiplos ambientes virtuais para analisar os vários hiperlinks disponíveis na interface digital. Se valeu também de vasta literatura que aborda as Teorias de Aprendizagem Tecnológicas, bem como os novos letramentos digitais demandados pelos residentes digitais, público das instituições educacionais do século 21.

\section{Resultados e discussão}

\subsection{Entre hiperlinks e outras cibervias: guiar a aprendizagem nos atalhos virtuais}

A multimodalidade vigente precisa gerar uma reflexão, não só sobre o formato que o conhecimento tem sido levado aos indivíduos, mas também como tem sido concebida na urgência do tempo. Resistir, adequar, adaptar, inovar, reaprender? Seja qual for a maneira encontrada, é preciso que se entenda que, em breve, será dado lugar a uma geração que está sendo frequentemente sufocada por contextos e formas conflitantes, que nem sempre dialogam com suas necessidades temporais. As multissemioses virtuais que permeiam a vida do indivíduo, em qualquer espaço que ele esteja inserido, tem provocado alterações na percepção do mesmo, de forma que em uma sociedade tecnológica, as linguagens utilizadas nos diversos meios precisam estar em consonância, para não causar um colapso perceptual de eventos, que pode vir a gerar um conflito de interpretações no seu processo de formação cognitiva.

Manusear estruturas físicas, como enciclopédias, na busca por uma consulta pautada em fundamentos críticos e científicos, demanda habilidades nem sempre desenvolvidas pelos residentes digitais. Em um único hiperlink os vinte volumes (ou mais) da mesma enciclopédia se revelam, como um caleidoscópio, fornecendo informações diretamente proporcionais à velocidade de um clique. Para Le Coadic,

Estrutura associativa que reproduz, muito de perto, a estrutura da memória humana e pode tornar-se seu complemento íntimo e ampliado. Permite substituir as estruturas clássicas arborescentes da informação por estruturas mais ricas e mais complexas, organizadas em redes, mostrando um mero infinito de caminhos, abertos a todas as navegações e interligando múltiplos objetos. (Le Coadic, 1996).

Tantos caminhos disponíveis, comuns para a interface digital, podem nos causar na formação do conhecimento em construção. O tráfego on-line se amplia, a cada dia, através das multitelas que se revelam ao usuário, desviando-o do foco. 
Medeiros ressalta que essa organização da página mostra que a tela, diferentemente de uma página convencional, pode ter a navegação, a leitura e a escrita como uma problemática, algo em aberto, para o leitor/autor escolher (Medeiros, 2014), ainda segundo a autora multiplicar significados por meio dos recursos dos modos visuais, onde diversos elementos concorrem e contribuem para a produção de sentidos. Para Kenski,

Hipertextos e hipermídias reconfiguraram a forma como lemos e acessamos as informações. A facilidade de navegação, manipulação e a liberdade de estrutura estimulam a parceria e a interação com o usuário. Ao ter acesso ao hipertexto, você não precisa ler tudo o que aparece na tela para depois seguir em frente. A estrutura do hipertexto permite que você salte entre os vários tipos de dados e encontre em algum lugar a informação que precisa. Com a hipermídia, acessamse informações em uma variedade enorme de formatos [...]. Mas é você que dá os saltos entre os muitos tipos de informações disponíveis e define o caminho que mais lhe interessa aprender. (Kenski, 2012).

Muitos são os meandros que podem seduzir o leitor na interface digital, desde a interseção de lincagens aos diversos recursos visuais que extrapolam as multitelas que surgem na interface digital. A condução de uma pesquisa ou até mesmo de uma simples leitura diante da tela do computador, demanda do sujeito mais foco do que na versão impressa. Essa visão caleidoscópica, mágica, pode levar a um desvio do propósito inicial da leitura. Pierre Lévy (1999) ressalta que o modelo informático é essencialmente plástico, dinâmico, dotado de uma certa autonomia de ação e reação. A Figura 1 exemplifica os múltiplos recursos aparentes de uma página virtual em uma interface digital.

Figura 1 - Recursos aparentes de uma página virtual em uma interface digital.

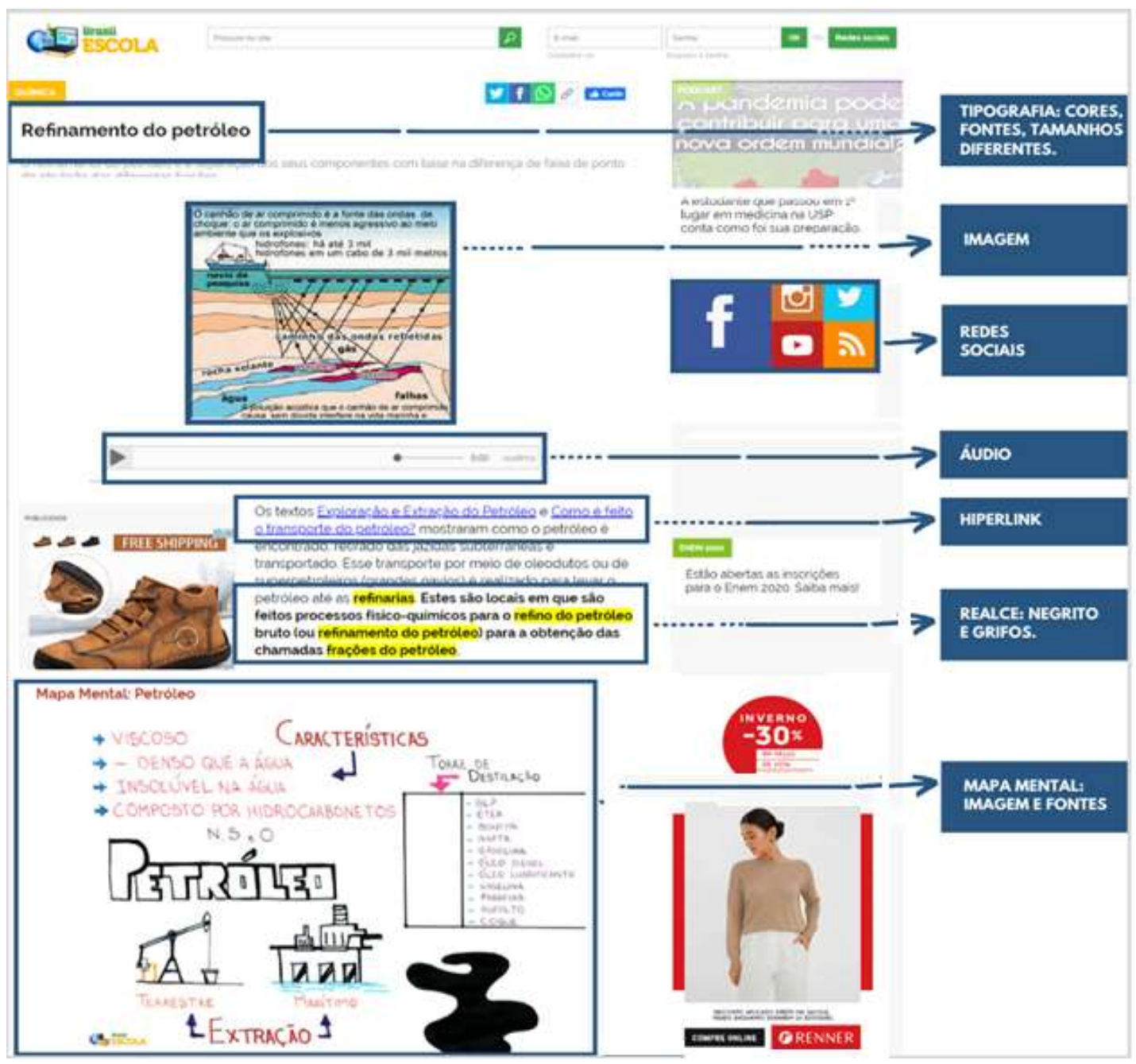

Fonte: Adaptado de Fogaça (2020). 
O gênero digital é repleto de termos e significados, sendo muitas vezes necessário recorrer a um portfólio (ou um dicionário) dos seus inúmeros termos, de forma que a inclusão no universo cibernético pode parecer, a princípio, um desafio intransponível para as pessoas nascidas no mundo analógico. Rojo (2013) afirma que o termo "modalidade" ou "modo" é utilizado para referir diferentes qualidades de percepção sensorial provocadas por diversas formas de produção dos sentidos, em que se envolvem "tecnologias" diferenciadas. O Quadro 1 a seguir apresenta um panorama teórico de como são delineados alguns termos recorrentes em textos que abordam o assunto Tecnologias Digitais da Informação e Comunicação (TDICs).

Quadro 1 - Panorama dos termos aplicados às TDICs.

\begin{tabular}{|c|c|}
\hline TERMO & ENTENDIMENTO \\
\hline CIBERESPAÇO & $\begin{array}{l}\text { O termo especifica não apenas a infraestrutura material da comunicação digital, mas } \\
\text { também o universo oceânico de informação que ela abriga, assim como os seres humanos } \\
\text { que navegam e alimentam esse universo (Lévy, 1999). Milhares de redes conectadas em } \\
\text { todo mundo e, em geral, é denominada rede, infovia ou ciberespaço. (Almeida, et al., 2014). }\end{array}$ \\
\hline HIPERTEXTO & $\begin{array}{l}\text { Rede composta de nós ligados por conexões. Os nós podem ser palavras, páginas, imagens, } \\
\text { sequências sonoras, referências a documentos (Kenski, 2012). São interativos e não } \\
\text { necessariamente lineares. }\end{array}$ \\
\hline HIPERMÍDIA & $\begin{array}{l}\text { São meios informacionais e comunicacionais que articulam representações visuais } \\
\text { animadas, representações sonoras e o próprio texto escrito, que também ganha movimento. } \\
\text { (Leite, 2015). }\end{array}$ \\
\hline MULTIMÍDIA & $\begin{array}{l}\text { Mistura de mídias variadas, podendo apresentar-se na mesma tela. Programa utilizado para } \\
\text { navegar na web. Permite utilizar praticamente todos os recursos da rede, como o correio } \\
\text { eletrônico, transferência de arquivos e acesso a grupos de discussão. (Kenski, 2012). }\end{array}$ \\
\hline MULTIMODALIDADE & $\begin{array}{l}\text { Uma característica da comunicação que se processa concomitantemente por várias formas } \\
\text { (escrita e leitura; gesto e fala; imagem e texto; áudio e vídeo). (Dicionário, 2020). Utiliza } \\
\text { diferentes linguagens/signos (letras, cores, sons, movimentos, design), [...] capaz de integrar } \\
\text { todas as categorias de signos para a construção de sentidos. (Coscarelli, 2016). }\end{array}$ \\
\hline MULTISSEMIOSE & $\begin{array}{l}\text { É a reunião imagética uma informação (na sua pluralidade), de modo que o leitor possa ter, } \\
\text { além do texto verbal, recursos visuais que corroboram na leitura e compreensão do } \\
\text { conteúdo pretendido. (Lima, 2015). }\end{array}$ \\
\hline SEMIÓTICA & $\begin{array}{l}\text { É o processo de significação e de produção dos significados. Uma área do conhecimento } \\
\text { que se ocupa de estudar os processos de produção, circulação e interpretação de signos. } \\
\text { (Mateus, 2015). }\end{array}$ \\
\hline SIGNO & $\begin{array}{l}\text { Resultado da interação entre uma representação, um objeto ou um evento representado é } \\
\text { algo ou alguém que irá associar a representação ao objeto ou ao evento representado. } \\
\text { (Mateus, 2015). }\end{array}$ \\
\hline
\end{tabular}

Fonte: Autores (2020).

Os caminhos que os hiperlinks, presentes nos textos virtuais, fornecem são repletos de intencionalidades, uma trilha de informações relacionadas: ampliação de sentido, tradução, associação, replicação, ou seja, qualquer elemento de um hipertexto (web) que faça referência a outro texto ou a outra parte deste ao alcance de um clique. Somam-se a tudo isso as diversas multimídias, como: redes sociais, marketing personalizado. E porque não citar áudio e vídeo, como recursos sedutores às multitelas da interface digital. Quanto mais recursos aparentes (sublinhados, destacados, iluminado), mais nós (distanciamento, hiato, fuga) são criados entre o que o usuário pretendia encontrar e o real texto que se constrói, após tantos desvios inocentes, fornecidos pelos hiperlinks. Essa customização dos hipertextos corrobora para outros pensamentos: De que forma o aluno constrói o seu repertório? De forma autêntica, sem replicar informações que destoam do propósito da pesquisa? Seriam os hiperlinks as entrelinhas do século XXI? Quais as perdas e os ganhos que tantos atalhos oferecem na construção do aprendizado do aluno? 
A mensagem subliminar que se revela ficará a cargo do itinerário adotado pelo usuário (aluno). Eis que entra a figura do professor, preparando a sua aula, elencando recortes pretendidos, diminuindo (não eliminando) os desvios da cibervia. Refletir acerca da sua função formadora, permite a adoção de estratégias singulares, que leva ao fomento de discussões significativas, como mote ampliador de uma aula, ou por se dizer sala de aula, seja essa amparada pelos muros da escola ou em outro ambiente de aprendizagem. Cada plataforma adotada para a realização do processo de ensino e aprendizagem requisita elementos peculiares para a aquisição do conhecimento pretendido. Desde o formato que se apresenta o conteúdo, passando pelo tempo de explanação, até a linguagem adotada para transmitir tais fundamentos.

\subsection{Entre upgrades e reconfigurações: a convergência nos ambientes de aprendizagem}

O professor, em parte visitante digital, que tem buscado se adaptar às novas gerações tecnológicas, precisa compreender que o público que frequenta suas salas de aula possui diferentes maneiras de compreender, transladar a informação apresentada, rompendo com paradigmas que os distanciam dos residentes digitais. É necessário se estruturar em um novo momento pedagógico tecnológico, desconstruir algumas resistências, compreender que aprender bem não desenvolvido pelas tecnologias recentes, mas que fazer o bom uso de tais recursos urge atualmente, e que tais multimídias apresentam amplos horizontes conceituais a serem explorados. Rojo (2013) ressalta que os ambientes virtuais de aprendizagem têm passado por grandes modificações, esses podem se basear em materiais autorrígidos e autossuficientes, sistemas de estímulos cognitivos, aprendizagem colaborativa, por perspectiva visual entre outros.

Para os educandos, o mundo se apresentou numa conformação diferente, sem tutores do conhecimento. Esses indivíduos fazem uma leitura própria do contexto apresentado, e só o significará se tal conceito fizer parte do seu repertório de vivências (aprendizagem situada). O estímulo das funções cognitivas do aluno digital passa por uma reconfiguração do conhecimento préexistente, sendo assimilado de uma forma diferente do sujeito analógico. A motivação pessoal é turbinada pela sua relação com o universo digital. Para Samussone, et al., (2021), as Tecnologias Digitais de Informação e Comunicação, TDICs, estão introduzidas no universo do discente em suas referências, imaginário e linguagem. Neto, et al., (Rojo, org., 2013) afirmam que há de se pensar que um ambiente propício aos multiletramentos/multiculturalismo/multissemioses deve considerar que o uso das tecnologias, a hibridação de mídias, a fluidez de conteúdos, a manipulação/processamento/difusão de informações está delineando outro perfil de aprendiz (aluno), que tem adotado novos e múltiplos processamentos de leitura e produção.

Os indivíduos que frequentam os ambientes da escola de educação básica (Fundamental e Médio), mais do que recorrer a concomitância das multitelas, vêm desenvolvendo habilidades e ações pareadas, sendo uma física, como: ler, escrever, correr, comer; com outra atrelada ao uso da tecnologia, como: enviar mensagem, assistir filme, jogar na interface virtual. A aparente alienação que por vezes demonstram, nem sempre se processa no seu intelecto, a dificuldade maior que os acompanha é, em grande parte, executar apenas uma das práticas solicitadas. Quando impelidos a realizarem apenas uma das ações, denotam certo estranhamento, já que seus hábitos vêm se desenvolvendo sobre dois pilares: o físico (tátil, palpável) e o virtual.

A convergência digital demanda uma reflexão acerca dos espaços presenciais de ensino. Acesso imediato, interatividade, respostas prontas por vezes sem fundamento, vão de encontro à cultura escolar, que estimula a formação integral do indivíduo pela aquisição do conhecimento. Para Henry Jenkins, norte-americano estudioso dos meios de comunicação e pesquisador dos meios de mídia, que durante os anos de 1993 e 2009 esteve à frente do programa de Estudos de Mídia Comparada do Instituto de Tecnologia de Massachusetts, as formas de comunicação tendem cada vez mais a convergirem para um único meio, que o mesmo denominou "Cultura da Convergência". Conforme o autor, convergência é,

[...] o fluxo de conteúdos através de múltiplas plataformas de mídia, a cooperação de múltiplos mercados midiáticos e [...] comportamento migratório dos públicos dos meios de comunicação que vão a quase qualquer parte, em busca das experiências de entretenimento que desejam. (Jenkins,2006). 
O fenômeno apontado por Jenkins tem causado mudanças significativas no comportamento das pessoas em conceber a produção de informação e uso delas. Cada indivíduo constrói sua própria formação, a partir de fragmentos extraídos de meios midiáticos, sociais, integrando-os de forma a compreender sua vida cotidiana. Ainda de acordo com o autor,

A convergência não ocorre por meio de aparelhos, por mais sofisticados que venham a ser. A convergência ocorre dentro dos cérebros de consumidores individuais e em suas interações sociais com outros. Cada um de nós constrói a própria mitologia pessoal, a partir de pedaços e fragmentos de informações extraídos do fluxo midiático e transformados em recursos através dos quais compreendemos nossa vida cotidiana. (Jenkins, 2006).

O conceito de presença no ambiente virtual extrapola a simples localização geográfica, abarcando a questão da linguagem falada e pensada. A harmonização das propostas disciplinares precisa criar um clima de agregação, se quiser promover um maior engajamento, que remete a uma ação voluntária de participação em determinada atividade, que se materializa quando uma pessoa se envolve por vontade própria. Para se alcançar tal feito em um ambiente escolar, é preciso conhecer o público alvo, sua linguagem prevalecente, seus objetivos e suas necessidades. Neto, et al., (Rojo, org., 2013) comentam que essa nova ética (novo ethos) surge em função das interações colaborativas, distributivas e compartilhadas nos ambientes virtuais, caracterizando um novo letramento menos centrado na materialidade textual (impressa).

Muitos elementos são necessários para guiar a criação do conteúdo almejado. Estar imerso na sala de aula permite contracenar com a geração que demanda os recursos pedagógicos virtuais diariamente. Para Bretonha, et al., (2020), essa proximidade possibilita encontrar carências didáticas do universo digital, já que muitas vezes os discentes se reportam ao professor para explicações mais detalhadas acerca dos fenômenos observados, que não fornece a amplitude conceitual necessária. Para gerar vínculos com os usuários é preciso personalizar os conteúdos, na interface, com recursos multimodais que atendam aos seus anseios, adotar uma abordagem com um tom mais informal, inserido em suas vivências, atendendo a um pensamento que esteja ligado às experiências de ações orientadas a um objetivo no mundo material. Coscarelli (2016) afirma que é importante pensar em perguntas que nortearão a elaboração da atividade, como: Onde você está? Para onde você vai? Por que você vai lá? O que você acha que vai encontrar lá? Vale a pena visitar tal página? Que caminho percorrer? Conhece o trajeto?

Uma sociedade que outrora fora cunhada por um pequeno grupo que controlavam as informações, está dando lugar a um cenário mais complexo de mídia. Cidadãos comuns que possuem habilidades peculiares diante dos novos letramentos digitais, conseguem expor seus pontos de vista sob uma nova ótica multimodal. O público tem a mídia e a comunicação em suas mãos, via smartphones, tablets, podendo com tais ferramentas inovar recontextualizando histórias, informações, propagando conhecimentos em um novo formato, que atenda ao seu espectador. Essa cultura participativa vem sendo impulsionada por grupos menores, multiplicando mídias em diferentes contextos.

O diálogo, aqui estabelecido, faz refletir sobre as formas de aprender, por meio de toda essa tecnologia e inovação, sem apenas recorrer a tutoriais nas redes, mas de ferramentas desenvolvidas de forma responsável, com a intenção de gerar conhecimento e preparar os discentes. É preciso atuar de maneira crítica no eixo informação/conhecimento versus aluno, minimizando o ruído informacional, levando ao pensamento crítico e responsável por parte desses, fazendo-os compreender que respostas na velocidade de um toque nem sempre favorecem a aprendizagem, conforme sugere Gómez,

$\mathrm{Na}$ era digital, o ato de aprender é mais um processo de assimilação do que de aquisição, de apropriação pessoal dos significados, proposições, modelos e mapas mentais que circulam, recriando-se continuamente nas redes de intercâmbio das quais cada indivíduo participa. Portanto, a criação ativa das nossas próprias redes de aprendizagem constitui uma autêntica aprendizagem na era digital. (Gómez, 2015).

O poder sinérgico e transformador da revolução tecnológica, apresenta em tempo real, um redesenho de um novo contexto de sociedade, em que todos os domínios, inclusive os educacionais, não estão passivos e alheios à tais mudanças. Seus integrantes precisam levantar as âncoras que os prendiam a pensamentos fechados e imutáveis e se permitir uma adaptação de 
contextos que urgem frente aos sujeitos que nasceram em uma dimensão bem mais ampliada. Nas palavras de Edgar Morin, em sua obra Os Sete Saberes Necessários à Educação do Futuro "necessitamos civilizar nossas teorias, ou seja, desenvolver nova geração de teorias abertas, racionais, críticas, reflexivas, autocríticas, aptas e autorreformar-se" (Morin, 2011).

\subsection{O ensino e a aprendizagem nas nuvens do século XXI}

A democratização da informação e do conhecimento precisa ser bem analisada pelos docentes junto aos discentes, se quiserem proporcionar em seus ambientes de estudo um local de fomento saudável de ideias. Levá-los à construção do pensamento crítico, proporciona aos mesmos a possibilidade de discernir entre o informativo e o cognoscitivo, em meio ao ouvir, refletir, mobilizar conhecimentos prévios, e se for producente alcançar à formação de um novo conhecimento. Para Gómez,

O desafio da escola contemporânea reside na dificuldade e na necessidade de transformar a enxurrada desorganizada e fragmentada de informações em conhecimento, ou seja, em corpos organizados de proposições, modelos, esquemas e mapas mentais que ajudem a entender melhor a realidade, bem como na dificuldade para esse conhecimento em pensamento e sabedoria. (Gómez, 2015).

Ser produtor de conteúdo, e não apenas consumidor momentâneo de informações desencontradas, é um processo que requer prática cotidiana desde a formação inicial do sujeito. A geração dos residentes digitais, por meio de suas profusas relações com o universo em rede, precisa ser estimulada a experimentar o mundo real, com práticas que demandam o pensamento crítico, e não apenas a mecanização do toque na interface da ferramenta digital, como se transportassem seus cérebros para a ponta dos dedos. Os ruídos causados pelo excesso de acessos por parte dos indivíduos usuários das redes, precisa ser repensada em esferas diversas, tanto no ambiente familiar, como no escolar. De acordo com Gómez,

O ensino frontal, simultâneo e homogêneo é incompatível com essa nova estrutura e exigirá dos professores o desenvolvimento de uma metodologia muito mais flexível e plural, bem como uma atenção mais personalizada aos estudantes. (Gómez, 2015).

Respostas imediatas de interlocutores virtuais, não privilegiam a formação do conhecimento humano. Interpretações vagas de leituras superficiais não levam à compreensão de conceitos ampliados. Kenski (2012) destaca que a escolha de determinado tipo de tecnologia altera profundamente a natureza do processo educacional e a comunicação entre os participantes. O hipertexto (HTML - Hypertext Markup Language) apresenta-se diante do leitor com um novo aspecto de conceber tipologia textual, com recursos fluidos, dinâmicos e até mesmo voláteis, repleto de interatividade em concomitância à pesquisa em curso. Em oposição a tipologia de Gutemberg, física, com início, meio e fim, rígida, com imagens inamovíveis, notas de rodapé (seriam esses os hiperlinks do século passado?), conceitos fechados em box centralizados (realce em negrito), entre outros recursos já cristalizados. Para Chartier,

Leitores manejam objetos cujas organizações comandam sua leitura, sua apreensão partindo do texto lido. Contra uma definição puramente semântica do texto, é preciso considerar que as formas produzem sentido, e que um texto estável na sua literalidade investe-se de uma significação e de um estatuto inédito quando mudam os dispositivos do objeto gráfico que o propõem à leitura. (Chartier,1991).

Compreender a necessidade dos letramentos digitais atinge esferas maiores do que àquela que se utiliza atualmente, como ferramentas modernas que emolduram aulas instrucionistas. Conforme Lidoino, Santos \& Reis (2020), o pensamento crítico do professor deve passar pelo desenvolvimento de competências a serem criadas e desenvolvidas em seus alunos, bem como se valer de algumas habilidades que esses já trazem consigo, ampliando-as nesse momento de reflexão do real significado de aprendizagem significativa. A educação sempre foi o caminho, já a tecnologia pode ser a estratégia. Os novos desafios para a escola contemporânea passam por algumas reestruturações de ordem filosófica, como ocorreram em outras épocas, procedimentais e atitudinais. Gómez expressa a respeito que "a fronteira entre o escolar e o não escolar já não é definida pelos 
limites do espaço e do tempo da escola, existe muito de 'não escola' no horário escolar e há muito 'de escola' no espaço e no tempo posterior ao horário escolar" (Gómez, 2015)

Algumas possíveis Teorias de Aprendizagem têm se apresentado diante do novo cenário que emerge nas escolas, com a utilização cada vez mais recorrente das Tecnologias Digitais de Informação e Comunicação, TDICs. As variadas formas de comunicação amparadas pelo uso das ferramentas digitais, têm levado os estudantes a se portarem, diante da construção da sua escolaridade, com perspectivas diferentes de como era feito no século passado, onde as propostas teóricas clássicas mais utilizadas foram desenvolvidas, como o Comportamentalismo (Behaviorismo), o Cognitivismo e o Humanismo. Algumas dessas propostas são apresentadas no Quadro 2 a seguir:

Quadro 2 - Teorias de aprendizagens recentes.

\begin{tabular}{|c|c|}
\hline TEORIAS DE APRENDIZAGEM & CARACTERÍSTICAS \\
\hline $\begin{array}{l}\text { TEORIA DA FLEXIBILIDADE } \\
\text { COGNITIVA }\end{array}$ & $\begin{array}{l}\text { Por flexibilidade cognitiva, queremos dizer capacidade para reestruturar o } \\
\text { conhecimento de alguém, de muitas maneiras, em uma resposta adaptável } \\
\text { para mudar radicalmente as exigências situacionais. (Spiro \& Jehng, 1990). }\end{array}$ \\
\hline TEORIA DA COGNIÇÃO SITUADA & $\begin{array}{l}\text { A cognição se distribui na mente, no corpo, nas atividades e nos ambientes } \\
\text { organizados culturalmente. (Lave \& Wenger, 1990). Podemos entender a } \\
\text { aprendizagem situada como algo contínuo de nossa participação no mundo } \\
\text { [...] aprendizagem é um aspecto integral e inseparável da prática social. (Lave } \\
\text { \& Wenger, 1990). }\end{array}$ \\
\hline $\begin{array}{l}\text { APRENDIZAGEM BASEADA EM } \\
\text { PROBLEMA/TEORIA DA } \\
\text { INSTRUÇÃO ANCORADA }\end{array}$ & $\begin{array}{l}\text { Aprendizagem se inicia com um problema a ser resolvido. Aprendizado } \\
\text { baseado em tecnologia. As atividades de aprendizado e ensino devem ser } \\
\text { criadas em torno de uma "âncora", que deve ser algum tipo de estudo de um } \\
\text { caso ou uma situação envolvendo um problema. (Bransford \& Stein the } \\
\text { CTGV, 1993). }\end{array}$ \\
\hline CONECTIVISMO & $\begin{array}{l}\text { Integração de princípios explorados pelo caos, rede, e teorias da } \\
\text { complexidade e auto-organização. A aprendizagem é um processo que ocorre } \\
\text { dentro de ambientes nebulosos onde os elementos centrais estão em mudança } \\
\text { - não inteiramente sob o controle das pessoas. A aprendizagem (definida } \\
\text { como conhecimento acionável) pode residir fora de nós mesmos (dentro de } \\
\text { uma organização ou base de dados), é focada em conectar conjuntos de } \\
\text { informações especializados, as conexões que nos capacitam a aprender mais } \\
\text { são mais importantes que nosso estado atual de conhecimento. (tradução da } \\
\text { autora). (Siemens, 2005). }\end{array}$ \\
\hline $\begin{array}{l}\text { TEORIA DA DISTÂNCIA } \\
\text { TRANSACIONAL }\end{array}$ & $\begin{array}{l}\text { A distância é um fenômeno pedagógico, e não simplesmente uma questão de } \\
\text { distância geográfica. (Moore \& Kearsley 2007). }\end{array}$ \\
\hline
\end{tabular}

Fonte: Autores (2020).

Mudanças disruptivas são visíveis na sociedade atual frente às novas ferramentas tecnológicas, bem como suas inúmeras possibilidades de interação entre pessoas e notícias em torno do planeta. Dentro das salas de aula as conexões são percebidas de forma latente, quando o aluno apresenta fatos e dados referente a assuntos que estão longe de serem abordados na aula, gerando discussões algumas vezes positivas, e por outras meros achismos (infundados), o que pode ser arriscado, já que de tais debates podem culminar ruídos de informações sobre assuntos sem fundamentos teóricos. Os autores Dudeney, Hockly \& Pegrum ressaltam,

Nas últimas décadas, vimos a transformação dos espaços físicos de aprendizagem: começamos a nos afastar de salas de aula rigidamente estruturadas, com suas inamovíveis fileiras de carteiras voltadas para o professor, indo em direção a espaços flexíveis, onde tudo, dos móveis às paredes podem ser reposicionados. Passados pouco mais de uma década, vimos uma versão acelerada da mesma transformação nos espaços virtuais de aprendizagem: inspirados na riqueza da web 2.0. [...] Realmente, os atuais contextos de aprendizagem são um híbrido de espaços físicos e virtuais que vão se sobrepondo, fluindo um para dentro do outro, amarrado pelas novas tecnologias. Num cenário ideal (e num crescente número de cenários do mundo real), espaços de aprendizagem físicos e virtuais fortalecem a plasticidade um do outro. (Dudeney, Hockly \& Pegrum, 2016). 
O bom uso das tecnologias requer um pensamento ampliado para além da ferramenta digital, na concepção de aprendizagem que ela pode contribuir para a formação dos discentes. Bacich, Neto e Trevizani (2015) ressaltam que o papel do professor como design de caminhos, de atividades individuais e de grupo, é decisivo e o faz de forma diferente [...]. O que a tecnologia traz hoje é a integração de todos os espaços e tempos. O ensinar e o aprender acontecem em uma interligação simbiótica, profunda e constante entre os chamados mundo físico e digital. Moran (2012) alega que ensinar e aprender exige hoje muito mais flexibilidade espaço temporal, pessoal e de grupo, menos conteúdos fixos e processos mais abertos de pesquisa e de comunicação. Esse deve ser o interesse maior para a construção de um aprendizado de sucesso.

A aproximação entre a pesquisa e o ensino, requer uma compreensão de aspectos que por vezes se encontram distantes um do outro, são esferas que se bem analisadas podem contribuir para o entendimento do processo educacional na sua magnitude. Investigar as demandas dos alunos dentro de uma proposta de ensino calcada na relevância do aprendizado, utilização de recursos que favoreçam um maior empenho dos participantes (professor e aluno), análise de partes interessadas buscando a estruturação de um plano de comunicação eficiente, definição robusta dos objetivos principais com um propósito muito bem definido, são alguns dos aspectos sobre o que de fato é necessário considerar para o cumprimento de um projeto educacional adequado para a realidade vigente. Mateus, Brasileiro e Silva (2015) alegam que é importante que as limitações dos recursos sejam discutidas com os estudantes.

Os residentes digitais transitam no ciberespaço e se valem dele em seus amplos aspectos, informação, lazer e cultura. Desenvolvem habilidades múltiplas de navegação, precisando ser orientados para uma leitura mais crítica dos materiais pesquisados em suas relações diretas e indiretas com o conteúdo pretendido. Kenski afirma que a linguagem digital, expressa em múltiplas TICs (Tecnologias da Informação e Comunicação), impõe mudanças radicais nas formas de acesso à informação, à cultura e ao entretenimento. $\mathrm{O}$ poder da linguagem digital, baseado no acesso a computadores e todos aos seus periféricos, à internet, aos jogos eletrônicos etc., com todas as possibilidades de convergência e sinergia entre as mais variadas aplicações dessas mídias, influencia cada vez mais a constituição do conhecimento, valores e atitudes. Cria uma nova cultura e uma outra realidade (Kenski, 2012).

Os residentes digitais desenvolvem habilidades em níveis recursivos como a compreensão e a decodificação dos fenômenos propostos nos exercícios virtuais. Para potencializar tais recursos o professor precisa elencar e propor exercícios, virtuais ou não, que leve o seu aluno a uma transposição de aptidões. Para Kenski “as novas TICs (Tecnologias da Informação e Comunicação) não são apenas meros suportes tecnológicos. Elas têm suas próprias lógicas, suas linguagens e maneiras particulares de comunicar-se com as capacidades perceptivas, emocionais, cognitivas, intuitivas e comunicativas das pessoas" (Kenski, 2012).

Oportunizar o diálogo entre o usuário e o material presente na interface digital possibilita a ampliação da confiabilidade no estudo em desenvolvimento. A criação de uma situação autêntica, cria vínculos permitindo a promoção de uma aprendizagem autônoma sem margem para o receio. Essa aproximação no ciberespaço agrega legitimidade à busca e obtenção do conhecimento pretendido por ambos, professor e aluno. A leitura e a percepção em ambientes virtuais exigem novos sítios de percepção. Gómez (2015) comenta que a utilização do recurso tecnológico é algo mais do que simplesmente utilizar as novas ferramentas para desenvolver tarefas antigas de maneira rápida, econômica e eficaz.

As novas atitudes pedagógicas advindas das Tecnologias Digitais de Informação e Comunicação, TDICs, tem proporcionado ao professor experimentar novas práticas, e possibilidades ampliadas, para levar seus alunos a atingir o conhecimento pretendido, mais do que uma opção, uma necessidade latente, frente aos materiais estruturantes cada vez mais concebidos para a interface digital, muitos deles autoexplicativos. Exercitar atitudes pedagógicas virtuais urge na atualidade, assim como a ampliação do pensamento para desbravar os diversos softwares já presentes nos domínios do ciberespaço. 


\section{Considerações Finais}

A ascensão de uma modalidade plástica de pensamento, que descompacta pré-requisitos conceituais, tem gerado sujeitos propensos para touchscreen, print, pinça, ou ainda designers de redes, sampleadores, youtubers, tiktokers, entre tantas outras habilidades desenvolvidas por esses usuários funcionais dos ambientes virtuais, sejam elas individuais ou sociais.

Mais do que avaliar pistas sutis nos hipertextos, classificando-os como pertinentes ou não, o discente precisa ser levado a refletir sobre as entrelinhas dos hiperlinks. O professor que integra essa rede de ensino e aprendizagem encontra-se diante dos novos desafios da sua função formadora: levar os alunos a evitar o desvio provocado pelas multitelas, resistir aos realces dos letterings, dos áudios e vídeos curtos que abreviam a construção do conhecimento, entre tantos outros itinerários oferecidos na interface digital, e focar na busca por aquilo que se almeja de início, a construção de um conhecimento calcado na relevância fundamentada.

Nesse aspecto pretende-se dar continuidade ao estudo da temática proposta com vistas às novas publicações, melhoria da prática docente e promover encontros formativos que ampliem a apropriação de recursos associados aos letramentos digitais, utilizando-se das novas posturas requeridas pelas Tecnologias Digitais de Informação e Comunicação.

\section{Agradecimentos}

Os autores agradecem aos colaboradores da Universidade Federal do Espírito Santo - Ufes, e aos envolvidos do Programa de Pós-Graduação do Mestrado Profissional em Química - Profqui, do Instituto Federal do Espírito Santo - Ifes, Campus Vila Velha.

\section{Referências}

Almeida, N. A. (coord.), Yamada, B. A. G. P., Manfredini, B. F., \& Alcici, S. A. R. (2014). Tecnologia na escola: abordagem pedagógica e abordagem técnica. Cengage Learning.

Bacich, L., Neto, A. T., \& Trevisani, F. de M. (2015). Ensino Híbrido: personalização e tecnologia na educação. Penso.

Bertonha, C. M., Bittencourt, M. T. \& Guanãbens, P. F. S., (2020). Avaliação do uso da educação a distância e do ensino remoto no ensino médio nos Institutos Federais da região sudeste antes e durante a pandemia por Covid-19. Research, Society and Development, 9(11), e90291110514, http://dx.doi.org/10.33448/rsdv9i11.10514.

Bransford, J. D., \& Stein, B.S. (1993). The Ideal Problem Solver. (2a ed.). Freeman.

Chartier, R. (1991). O mundo como representação. Estudos avançados, 11(5),173-191.

Coscarelli, C. V. (2016). Tecnologias para aprender. Parábola editorial.

Demo, P. (2009). Aprendizagens e Novas Tecnologias. Revista Brasileira de Docência, Ensino e Pesquisa em Educação Física. 1(1), 53-75.

Dicionário online de Português (2019). Letramento. Disponível em: https://www.dicio.com.br/letramento/.

Dudeney, G., Hokly, N., \& Pegrun, M. (2016). Letramentos digitais. Parábola Editorial.

Fogaça, J. R. V.(2020) Refinamento do petróleo. Brasil Escola. Disponível em: https://brasilescola.uol.com.br/quimica/refinamento-petroleo.htm.

Gómez, A. I. P. (2015). Educação na era digital: a escola educativa. Penso.

Jenkins, H. (2009). Cultura da convergência: a colisão entre os velhos e novos meios de comunicação. (2a ed.). Aleph

Jenkins, H., Clinton, K., Purushotma, R., Robison, A. J., \& Weigel, M. (2006). Confronting the Challenges of Participatory Culture: Media Education for the 21 st Century. Occasional Paper. Boston, MA: MIT/MacArthur Foundation.

Kaurk, F. S., Manhães, F. C., \& Medeiros, C. H. (2010). Metodologia da Pesquisa: um guia prático. via litterarum.

Kenski, V. M. (2012). Educação e tecnologia: os novos ritmos da informação. (8a ed.). Papirus.

Lave, J., \& Wenger, E. (1990). Situated Learning: legitimate periperal participation. Cambridge, UK: Cambridge University Press.

Le C., Yves-F. (1996). A ciência da informação. Brasília: Briquet de Lemos/Livros.

Leite, B. S. (2015). Tecnologia no ensino de química: teoria e prática na formação docente. Appris, 
Research, Society and Development, v. 10, n. 8, e32710817492, 2021

(CC BY 4.0) | ISSN 2525-3409 | DOI: http://dx.doi.org/10.33448/rsd-v10i8.17492

Lévy, P. (1996). As tecnologias da inteligência: o futuro do pensamento na era da informática. Ed. 34.

Lévy, P. (1999). Cibercultura. Editora 34.

Lidoino, A. C. P., dos Santos, D. M., \& Reis, G. A. (2020). Reflexões sobre a formação continuada de professores na contemporaneidade. Research, Society and Development, 9(9), e19996473, 2020, https://doi.org/10.33448/rsd-v9i9.6473.

Lima, E. A. de. (2015). Multimodalidade e leitura crítica: novas perspectivas para o ensino de língua portuguesa. Dissertação (Mestrado). UERN, Pau dos Ferros, RN.

Mateus, A. L. (2015). Ensino de química mediado pelas TICs. Ed. UFMG.

Medeiros, Z. (2014). Gêneros, multimodalidade e letramentos: Genres, Multimodality, and Literacies. RBLA, 14(3), 581-612.

Moran, J. M. (2012). A educação que desejamos: novos desafios e como chegar lá. (5a ed.). Papirus.

Moore, M. G., \& Kearsley, G. (2007). Educação a distância: uma visão integrada. Thomson Learning.

Morin, E. (2011). Os sete saberes necessários à educação do futuro. (2a ed.). Cortez.

Rojo, R. (2013).Escol@ Conectada: os multiletramentos e as TICs. Parábola.

Samussone, L. B., Silveira, S. F. R., Júnior, A. C. B., Alexandre, D. C. S. \& Reis, A.O. (2021). Fatores condicionantes para a tendência do uso de tecnologias de informação e comunicação (TIC) no ensino superior em Moçambique. Research, Society and Development, 10 (6), e 56910616053, http://dx.doi.org/10.33448/rsd-v10i6.16053

Siemens, G. (2005). Connectivism: a learning theory for the digital age. International Journal of Instructional Technology \& Distance Learning, 2 (1). http://itdl.org/Journal/Jan_05/article01.htm.

Spiro, R. J., Jehng, J. (1990) Cognitive flexibility and hypertext: theory and technology for the non-linear and multidimensional traversal of complex subject matter. Cognition, Education, and Multimedia. Erlbaum. 